\title{
A Idade e Natureza da Fonte do Granito do Moinho, Faixa Ribeira, Sudeste do Estado de São Paulo
}

\author{
Colombo Celso Gaeta Tassinari ${ }^{1}$ (ccgtassi@usp.br), Marly Babinski1 ${ }^{1}$, Allen P. Nutman² \\ ${ }^{1}$ Departamento de Mineralogia e G eotectônica - Instituto de Geociências - USP \\ R. do Lago 562, CEP 05508-080, São Paulo, SP, BRA \\ ${ }^{2}$ Research School of Earth Sciences - Australian National University, Canberra, AUS
}

Palavras-chave: Faixa Ribeira; Ciclo Brasiliano; Granitos; Geocronologia U-Pb.

RESUMO

Este trabalho apresenta novos dados geocronológicos U-Pb SHRIMP em zircões e Sm-Nd em rocha total do Granito do Moinho, que ocorre nas imediações da cidade de Nazaré Paulista, Estado de São Paulo. Este granito apresenta característica sin- a tardi-tectônica em relação à Orogenia Brasiliana e é intrusivo nas sequiências mesoproterozóicas do Grupo Serra do Itaberaba, no segmento central da Faixa de Dobramentos Ribeira. Adicionalmente, foram reavaliados dados isotópicos de $\mathrm{Pb}$ obtidos em amostras de rocha total e feldspatos potássicos disponíveis na literatura. A idade U-Pb SHRIMP obtida em monocristais de zircões ígneos do granito foi de $620 \pm 11 \mathrm{Ma}$, sendo interpretada como a época de cristalização desta rocha. As idades modelo Sm-Nd obtidas situaram-se entre 2,0 e 1,9 Ga, mostrando que o magma foi produzido por fusão parcial de rochas pré-existentes, derivadas do manto superior no Paleoproterozóico. As composições isotópicas de $\mathrm{Pb}$ das amostras do Granito do Moinho indicam, a exemplo dos isótopos de Nd, uma fonte também crustal e com participação de rochas do Grupo Serra do Itaberaba, de idade mesoproterozóica.

Keywords: Ribeira belt, Brasiliano cycle, granites, U-Pb geochronology.

\section{ABSTRACT}

U-Pb SHRIMP zircon ages and Sm-Nd isotopic analyses were carried out on the syn- to late tectonic Moinho Granite, intruded within the Mesoproterozoic Serra do Itaberaba Group. Six U-Pb SHRIMP analyses were undertaken on oscillatory zoned zircons. All yielded close to concordant Neoproterozoic ages, with a ${ }^{206} \mathrm{~Pb} /{ }^{238} \mathrm{U}$ weighted mean age of $620 \pm 11 \mathrm{Ma}$, interpreted as the time of the granite crystallization. Sm-Nd isotopic analyses on samples from the Moinho Granite presented Paleoproterozoic depleted-mantle model ages between 2.0 and $1.9 \mathrm{Ga}$, and negative $\varepsilon_{\mathrm{Nd}}$ values, indicating continental sources for the granitic magma. Previous $\mathrm{Pb}$ isotopic data suggest that the Mesoproterozoic Serra do Itaberaba metasedimentary sequence contributed to the magma genesis of the studied granitoid. 


\section{INTRO DUÇÃO}

O denominado "Granito do Moinho" ocorre à leste da cidade de Nazaré Paulista, no Estado de São Paulo, intrusivo nas rochas metamórficas do Grupo Serra do Itaberaba, constituindo um corpo de $c a$. $6 \mathrm{~km}$ de extensão e largura média de 750 metros. Este granitóide foi considerado por Campos Neto et al. (1983) como um corpo sin- a tardi-tectônico em relação ao Ciclo Orogênico Brasiliano.

Análises isotópicas de $\mathrm{Pb}$ obtidas em amostras de rocha total deste granitóide (Tassinari, 1988) definem um trend no diagrama ${ }^{207} \mathrm{~Pb} /{ }^{204} \mathrm{~Pb}$ versus ${ }^{206} \mathrm{~Pb} /{ }^{204} \mathrm{~Pb}$ cuja inclinação indica uma idade de $c a$. 1,2 Ga, sugerindo que pelo menos parte do $\mathrm{Pb}$ presente no granito seria proveniente de rochas mesoproterozóicas.

Com o objetivo de definir com precisão a idade de cristalização do Granito do Moinho e a natureza de suas fontes magmáticas, além de verificar o real significado dos dados isotópicos de $\mathrm{Pb}$ previamente obtidos, foram realizadas análises U-Pb SHRIMP (Sensitive High Resolution Ion Microprobe) em zircões, análise Sm-Nd em rocha total e uma reavaliação dos dados isotópicos de $\mathrm{Pb}$ disponíveis, que foram interpretados à luz dos dados geológicos atualmente disponíveis para a área.

\section{CONTEXTO GEOLÓGICO}

A Faixa de Dobramentos Ribeira (Almeida, 1976), de idade Neoproterozóica, estende-se ao longo da região sudeste do Brasil, compreendendo um sistema orogênico que bordeja os Crátons do São Francisco e do Congo, bem como do bloco cratônico inferido, situado abaixo das rochas sedimentares paleozóicas da Bacia do Paraná. O sistema orogênico Ribeira foi ativo durante o final do Neoproterozóico e início do Paleozóico, retrabalhando rochas de idades arqueanas e paleoproterozóicas, durante a amalgamação do Supercontinente Gondwana (Campos Neto e Figueiredo, 1995; Tassinari e Sato, 1996; Dias Neto et al., 2000; Dantas et al., 2000).

O segmento central da Faixa de Dobramentos Ribeira no estado de São Paulo é composto por três diferentes domínios geológicos (Costeiro, Embu e São Roque) separados por extensas zonas de cisalhamentos (Figura 1), que diferem entre si pelas idades de seus respectivos protólitos crustais, pelas assembléias litológicas e histórias geológicas.

O Domínio Costeiro consiste de rochas metassedimentares de médio a alto grau metamórfico, cuja evolução metamórfica iniciou-se em 590 Ma e seu resfriamento regional ocorreu há ca. 480 Ma (Dias Neto et al., 2000). Estes gnaisses kinzigíticos foram formados principalmente a partir de materiais crustais de idade paleoproterozóica $(2,0$ 1,8 Ga; Tassinari e Campos Neto, 1988) e são intrudidos por granitóides neoproterozóicos de diversas naturezas. O Domínio representado pelo Complexo Embu é composto por terrenos gnáissico-migmatíticos neoproterozóicos, formados por processos de fusão parcial de rochas paleoproterozóicas e arqueanas (Tassinari e Campos Neto, 1988; Babinski et al., 2001), contendo rochas metassedimentares de baixo grau, preservadas em calhas sinclinoriais e granitóides intrusivos neoproterozóicos. O Domínio São Roque é composto pelas seqüências metavulcanosedimentares dos Grupos Serra do Itaberaba e São Roque, sendo o primeiro de idade meso- e neoproterozóica (Juliani et al., 2000) e o segundo de idade neoproterozóica (Hackspacker et al., 2000).

Os dados geocronológicos atualmente disponíveis para as rochas do Domínio São Roque (Tassinari e Campos Neto, 1988; Ragatki, 1997; Hackspacker et al., 2000) indicam que o início da sedimentação do Grupo Serra do Itaberaba ocorreu há 1395 Ma (Juliani et al., 2000). Sobrepostos a este grupo ocorrem os metaconglomerados do Grupo São Roque, cujos seixos de composição granítica forneceram uma idade isocrônica $\mathrm{Rb}$ - $\mathrm{Sr}$, em amostras de rocha total, de $c a$. 1,2 Ga (Tassinari et al., 1985), indicando uma possível proveniência de rochas associadas à evolução tectono-magmática do Mesoproterozóico. Análises isotópicas K-Ar em biotitas da matriz deste metaconglomerado resultaram em idades de ca. de 620 Ma (Tassinari et al., 1985), evidenciando que nesta época a temperatura regional já atingia patamares próximos a $300-250^{\circ} \mathrm{C}$. Em adição, Hackspacher et al. (2000) obtiveram a idade de $628 \pm 9$ Ma para os metabasaltos da Formação Pirapora, que foi interpretada como a idade de cristalização destas rochas. Segundo Tassinari et al. (2001) esta idade estaria associada, portanto, à época de geração de crosta oceânica do Ofiolito de Pirapora, que teria sua colocação tectônica ocorrida há 620 - $600 \mathrm{Ma}$.

Inúmeros corpos de granitóides com variações texturais, mineralógicas e composicionais, muitos deles com características cálcio-alcalinas e álcali-cálcicas intrudiram a sequiência dos Grupos São Roque e Serra do Itaberaba durante sua evolução, desde a fase sin- a tardi-tectônica até a pós-tectônica (Janasi e Ulbrich, 1992).

O Granito do Moinho, objeto deste estudo, situa-se entre os corpos intrusivos no grupo Serra do Itaberaba, onde ocorrem também os maciços do Barro Branco, Pedra Branca e Mato Mole. As relações entre estes granitóides foram traçadas por Campos Neto et al. (1988), com base nas características estruturais das rochas, tendo sido considerado o Maciço de Barro Branco, datado por Ragatki (1997) em $629 \pm 11 \mathrm{Ma}$ (U-Pb convencional em zircões, intercepto superior), relacionado ao magmatismo pré- a sin-foliação $S_{1}$, que seria mais antigo que o Granito do Moinho, considerado como tardi-D 1 . O granitóide da Pedra Branca, datado em $540 \pm 90 \mathrm{Ma}$ (IPT, 1984, Isócrona Rb-Sr em rocha total), seria 


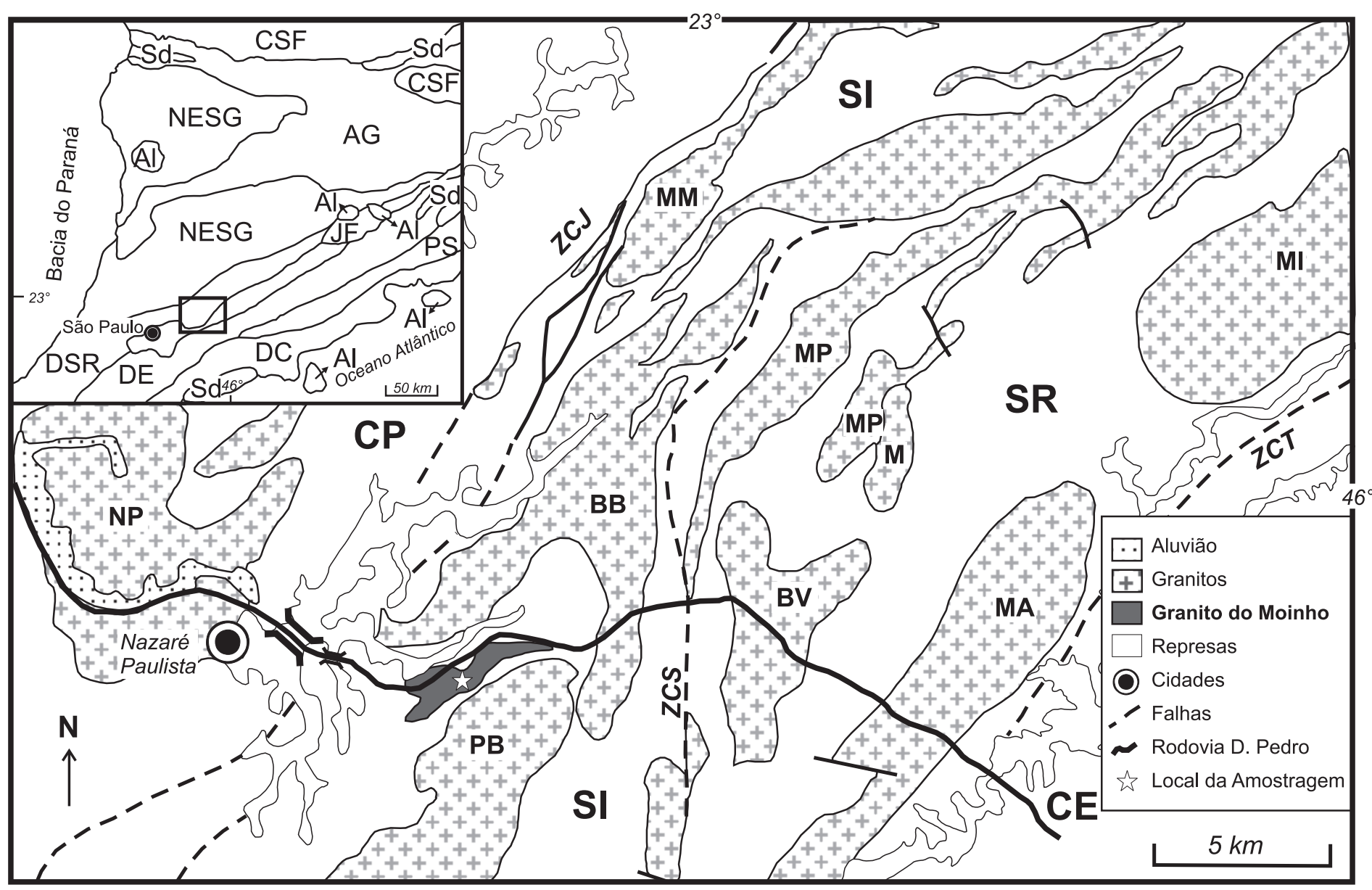

Figura 1. Esboço geológico do Domínio São Roque e localização do Granito do Moinho (modificado de Campos Neto et al., 1983). Mapa menor (Domínios tectônicos): JF = Domínio Juiz de Fora, NESG = Nappe de Empurrão Socorro-Guaxupé, SR = Domínio São Roque, $\mathbf{D E}=$ Domínio Embu, $\mathbf{A G}=$ Faixa Alto Rio Grande, $\mathbf{C S F}=$ Cráton do São Francisco, $\mathbf{S d}=$ Bacias Sedimentares Al = Intrusões Alcalinas, DC = Domínio Costeiro, PS = Domínio Paraíba do Sul. Mapa maior: MP = Maciço Morro do Pão, MA = Maciço Morro Azul, NP = Maciço Nazaré Paulista, $\mathbf{M}=$ Maciço Machado, BV = Maciço Boa Vista, $\mathbf{M I}=$ Maciço Imbiruçu, $\mathbf{B B}=$ Maciço Barro Branco, $\mathbf{Z C}=$ Zona de Cisalhamento $(\mathbf{S}=$ Sertãozinho, $\mathbf{J}=$ J undiuvira, $\mathbf{T}=$ Taxaquara $), \mathbf{C P}=$ Complexo 
sin- $\mathrm{D}_{2}$, ou conforme Juliani (1993), parte dele não possui evidências de deformação sendo, portanto, mais jovem.

As rochas do Granito do Moinho são inequigranulares e, em alguns locais, porfiríticas. A granulação é predominantemente média e a composição é granodiorítica. Apresentam coloração cinza, por vezes rosa, devido à presença de megacristais de feldspato potássico. A mineralogia característica é composta por plagioclásio, feldspato potássico, quartzo, biotita, hornblenda e opacos ocorrem subordinadamente. Conforme Campos Neto et al. (1983), estas rochas exibem estruturas levemente orientadas segundo a direção regional NE-SW, representada por uma foliação tectônica, com desenvolvimento local de faixas protomiloníticas a miloníticas.

Do ponto de vista geoquímico, Ragatki (1997) estudou em detalhe as rochas graníticas intrusivas no Grupo Serra do Itaberaba, que ocorrem na área deste estudo, tendo caracterizado as amostras do Granito do Moinho como do tipo 3B de Streickeisen (1974), com valores de $\mathrm{SiO}_{2}$ de 64\%, podendo chegar até $70,5 \%$ para os termos mais diferenciados, e com padrão de Elementos Terras Raras enriquecido em ETR leves.

\section{PROCEDIMENTOS ANALÍTICOS}

As análises isotópicas U-Pb em zircões separados de uma amostra do Granito do Moinho coletada nas proximidades da Rodovia Dom Pedro I, no Bairro do Moinho, à cerca de $7 \mathrm{~km}$ da cidade de Nazaré Paulista, sentido Igaratá, foram realizadas na Australian National University no equipamento SHRIMP I (Sensitive High Resolution Ion Microprobe), utilizando-se um feixe de $\mathrm{O}_{2}$ com $20 \mu \mathrm{m}$ de diâmetro. Detalhes sobre os procedimentos analíticos e calibração do aparelho são reportados em Stern (1998) e Williams (1998). As razões ${ }^{206} \mathrm{~Pb} /{ }^{238} \mathrm{U}$ têm um componente de erro de $1,5 \%$ devido à calibração das medidas em relação aos zircões padrões. O cálculo da abundância de U foi calibrado em relação ao monocristal de zircão padrão SL13 com 238 ppm de U, e a razão $\mathrm{Pb} / \mathrm{U}$ foi calibrada em relação ao padrão AS57 (Paces e Miller, 1993). Todos os erros levaram em consideração as flutuações não lineares das taxas de contagens de íons além daquelas esperadas a partir das contagens estatísticas (Stern, 1998).

As constantes de desintegração e a razão atual ${ }^{238} U /{ }^{235} U$ utilizadas nos cálculos são aquelas fornecidas por Steiger e Jäger (1977). Para zircões neoproterozóicos, que é o caso das amostras estudadas, os dados mais confiáveis são aqueles derivados das razões ${ }^{206} \mathrm{~Pb} /{ }^{238} \mathrm{U}$, fazendo-se a correção para $\mathrm{Pb}$ comum através do ${ }^{207} \mathrm{~Pb}$ (Compstom et al., 1984) usando a composição de $\mathrm{Pb}$ proposta pelo modelo de Cumming e Richards (1975) para o cálculo das idades individuais dos zircões. O cálculo da idade integrada dos zircões foi feito pela média ponderada usando o programa ISOPLOT de Ludwig (1998) e estão representados no diagrama Tera-Wasserburg $\left({ }^{238} \mathrm{U} /{ }^{206} \mathrm{~Pb}\right.$ versus $\left.{ }^{207} \mathrm{~Pb} /{ }^{206} \mathrm{~Pb}\right)$.

A análise Sm-Nd foi realizada no Centro de Pesquisas Geocronológicas do Instituto de Geociências da Universidade de São Paulo, e os procedimentos analíticos estão descritos em Sato et al. (1995). As análises espectrométricas foram realizadas no espectrômetro de massa Finnigan 262. As razões isotópicas de Nd foram normalizadas para ${ }^{146} \mathrm{Nd} /{ }^{144} \mathrm{Nd}=0,72190$. A média das razões de ${ }^{143} \mathrm{Nd} /{ }^{144} \mathrm{Nd}$ para os padrões de La Jolla e BCR-1 foi de $0,51185 \pm 0,00005(2 \sigma)$ e $0,51266 \pm 0,00005(2 \sigma)$, respectivamente. Os brancos analíticos de $\mathrm{Sm}$ e $\mathrm{Nd}$ foram de $80 \mathrm{pg}$ e $100 \mathrm{pg}$, respectivamente. As idades modelo manto-empobrecido $\left(\mathrm{T}_{\mathrm{DM}}\right)$ foram calculadas segundo DePaolo (1981).

\section{RESULTADOS E DISCUSSÃO}

Os zircões separados da amostra SP-02 do Granito do Moinho são claros, por vezes amarelados formando prismas euhedrais a subeuhedrais de 150 a $300 \mu \mathrm{m}$ de comprimento. Nas imagens de catodoluminescência (CL) muitos dos grãos mostram uma zonação oscilatória bem desenvolvida paralela ou não à forma externa dos cristais. A zonação oscilatória observada é similar àquelas geradas em zircões magmáticos e que tiveram uma taxa de crescimento lenta (Vavra, 1990). Localmente a zonação oscilatória é interrompida por domínios de recristalização discordante (Figura 2), cujo significado ainda não é compreendido.

Seis análises pontuais foram realizadas em seis diferentes cristais de zircão, todos mostrando zonação oscilatória, e os dados analíticos estão apresentados na Tabela 1. Todas as análises indicaram idades concordantes neoproterozóicas, com os dados fornecendo uma idade média ${ }^{206} \mathrm{~Pb} /{ }^{238} \mathrm{U}$ de $620 \pm 11 \mathrm{Ma}$ (95\% de confiança) e valor de MSWD de 0,6 (Figura 3). Devido à morfologia ígnea dos zircões analisados esta idade é aqui interpretada como a época de cristalização do Granito do Moinho.

As análises isotópicas de $\mathrm{Pb}$ em rocha total do Granito do Moinho apresentadas em Tassinari (1988) foram re-interpretadas neste trabalho, com base nos atuais conhecimentos geológicos. Os pontos analíticos relativos a estas análises (Tabela 2), quando lançados no diagrama ${ }^{207} \mathrm{~Pb} /{ }^{204} \mathrm{~Pb}$ versus ${ }^{206} \mathrm{~Pb} /{ }^{204} \mathrm{~Pb}$ mostram um alinhamento cuja inclinação sugere uma idade de 1,2 Ga (Figura 4) que não representa a idade de cristalização do granito.

Diferentemente do esperado, os dados isotópicos obtidos nos feldspatos potássicos não se ajustam ao alinhamento definido pelas amostras de rocha-total, mostrandose mais radiogênicos. Dois argumentos podem ser usados para justificar este comportamento: 


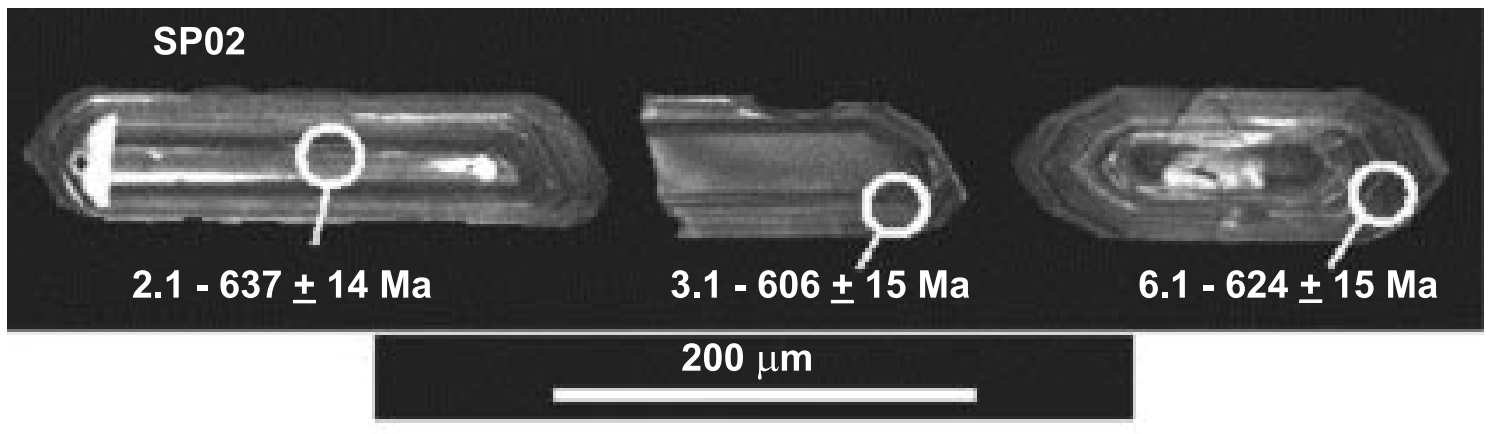

Figura 2. Imagens de catodoluminescência dos grãos representativos de zircões datados. Os pontos assinalados referem-se aos locais analisados.

Tabela 1. Dados analíticos das análises U-Pb SHRIMP nos zircões do Granito do Moinho.

\begin{tabular}{|c|c|c|c|c|c|c|c|c|c|c|c|}
\hline Análise & $\begin{array}{c}\text { Tipo do } \\
\text { cristal }\end{array}$ & $\begin{array}{c}\text { U } \\
\text { ppm }\end{array}$ & $\begin{array}{c}\text { Th } \\
\text { ppm }\end{array}$ & Th/U & $\begin{array}{l}\%{ }^{206} \mathrm{~Pb} \\
\text { comum }\end{array}$ & ${ }^{206} \mathrm{~Pb}^{206} \mathrm{~Pb}^{*}$ & ${ }^{207} \mathrm{~Pb} /{ }^{206} \mathrm{~Pb}^{*}$ & ${ }^{207} \mathrm{~Pb}^{206} \mathrm{~Pb}^{\star *}$ & ${ }^{238} \mathrm{U}^{206} \mathrm{~Pb}^{*}$ & ${ }^{238} \mathrm{U} /{ }^{206} \mathrm{~Pb}^{* *}$ & $\begin{array}{c}\text { Idade (Ma) } \\
{ }^{206} \mathrm{~Pb}^{238} \mathrm{U}^{\star * *}\end{array}$ \\
\hline 1.1 & $e, o s c, p$ & 336 & 128 & 0,38 & $0,29 \pm 0,08$ & 5330 & $0,0615 \pm 0,0007$ & $, 0588 \pm 0,0015$ & $9,975 \pm 0,223$ & $10,009 \pm 0,224$ & $614 \pm 13$ \\
\hline 2.1 & osc,p & 224 & 162 & 0,72 & $0,31 \pm 0,16$ & 2221 & 13 & 0,055 & $9,602 \pm 0$ & & \\
\hline 3.1 & $e, o s c, p$ & 251 & 117 & 0,47 & $0,11 \pm 0$ & & & 0,0577 & 10,129 & 10,158 & \\
\hline 4.1 & $o s c, p$ & 331 & 209 & 0,63 & $0,22 \pm c$ & 18727 & $0610 \pm 0,0$ & 0,0602 & 9,769 & 9,779 & \pm 15 \\
\hline 5 & $s c, p$ & 334 & 179 & 0,53 & $0,15 \pm$ & 100 & & 0,06 & 10,00 & $10,0 c$ & \\
\hline & $e, o s c, p$ & 490 & 379 & 0,77 & $0,10 \pm 0,09$ & 12801 & $0,0599 \pm 0,0007$ & $0,0588 \pm 0,0011$ & $9,830 \pm 0,241$ & $9,843 \pm 0,241$ & $624 \pm 15$ \\
\hline
\end{tabular}

Notas: Análise: x.y; número do grão seguido pelo número da análise. Hábito do cristal: $\mathbf{p}=$ prismático (razão altura/largura $>2$ ). Local da análise: $\mathbf{e}=$ borda do cristal. Microestrutura do cristal em imagem de catodoluminescência: osc = zoneamento oscilatório.

* Razões isotópicas não corrigidas. ** Razões isotópicas corrigidas para $\mathrm{Pb}$ comum. ${ }^{* * *}$ Idade corrigida para $\mathrm{Pb}$ comum pelo modelo de Cumming e Richards (1975) para a provável idade da rocha. Idade em Ma, $\pm 2 \sigma$.

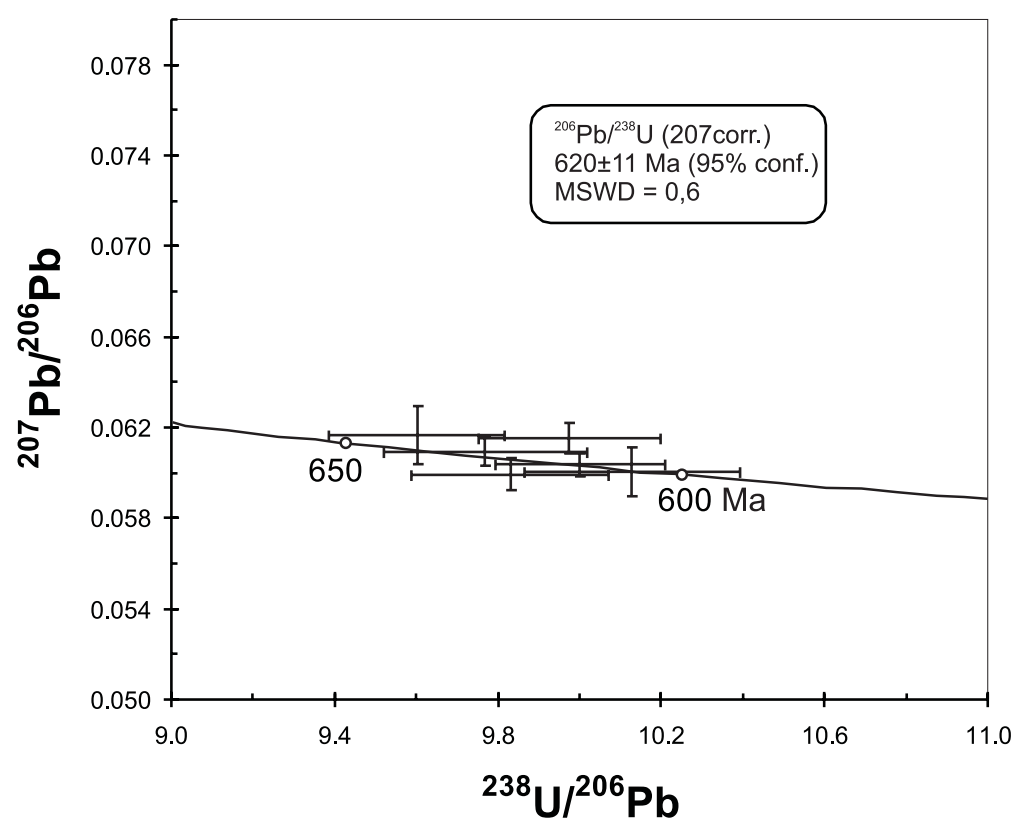

Figura 3. Diagrama Concórdia Tera-Wasserburg para zircões do Granito do Moinho. O s erros dos pontos analíticos são $2 \sigma$. 
1. pelo fato de não ter sido usada a técnica de lixiviação na análise dos feldspatos (Housh e Bowring, 1991), atualmente obrigatória neste tipo de estudo, já que permite a separação de $\mathrm{Pb}$ radiogênico incorporado no mineral durante processos tardios (alteração e/ou percolação de fluidos), as razões isotópicas obtidas representariam valores médios entre as razões iniciais de $\mathrm{Pb}$ do magma e aquelas de fluidos tardios;

2. a presença de inclusões de xenocristais antigos e ricos em U nos feldspatos, as quais produziriam razões ${ }^{207} \mathrm{~Pb} /{ }^{204} \mathrm{~Pb}$ mais radiogênicas que as do magma parental.

Levando-se em conta as considerações acima mencionadas, o posicionamento dos pontos analíticos dos feldspatos no diagrama uranogênico do modelo de Plumbotectônica (Figura 5a) não representaria a verdadeira fonte do magma. Como as razões ${ }^{207} \mathrm{~Pb} /{ }^{204} \mathrm{~Pb}$ se mostraram mais contaminadas, o posicionamento correto dos pontos deveria ser em direção às curvas relativas ao manto e à crosta inferior (menos radiogênicas). Entretanto, no diagrama toriogênico (Figura 5b) observa-se claramente que os pontos situam-se entre as curvas relativas ao ambiente orogênico e crosta inferior (alta razão $\mathrm{Th} / \mathrm{Pb}$ ), sugerindo que este último reservatório contribuiu de forma significativa na geração do magma parental do Granito do Moinho.

Neste trabalho foi também realizada uma análise $\mathrm{Sm}-\mathrm{Nd}$ em rocha total da mesma amostra de onde foram separados os zircões datados, que indicou uma idade modelo mantoempobrecido $\left(\mathrm{T}_{\mathrm{DM}}\right)$ de $2,1 \mathrm{Ga}$ e um valor de $\boldsymbol{\varepsilon}_{\mathrm{Nd}}$, calculado para 620 Ma de -13,2 (Tabela 3). Ragatki (1997) e Tassinari e Sato (1996) também apresentam dados Sm-Nd para o Granito do Moinho, fornecendo respectivamente idades $\mathrm{T}_{\mathrm{DM}}$ de 1,9 e $2,1 \mathrm{Ga}$ e valores de $\boldsymbol{\varepsilon}_{\mathrm{Nd}}$, calculados também para $620 \mathrm{Ma}$, de -11,2 e -14,5, respectivamente. Estes dados (Tabela 3 ) indicam que o magma parental responsável pela formação das rochas que sofreram fusão parcial para gerar o Granito do Moinho diferenciou-se do manto superior durante a orogenia Transamazônica, no Paleoproterozóico. A variação observada nas idades modelo Sm-Nd deve-se, provavelmente, à heterogeneidade das fontes que geraram o magma granítico, e também contaminações diferenciais por rochas da crosta superior, tais como as rochas que constituem a seqüência metavulcano-sedimentar do Grupo Serra do Itaberaba, o que poderia ter tornado os valores de $\boldsymbol{\varepsilon}_{\mathrm{Nd}}$ mais negativos.

Integrando-se a interpretação dos dados isotópicos de $\mathrm{Pb}$ e $\mathrm{Nd}$ com as informações geológicas disponíveis (Juliani et al., 2000), é possível considerar que o magma parental do granito do Moinho foi formado a partir de fusão parcial de rochas características da crosta inferior, com idades paleoproterozóicas, e sofreu também contaminação de rochas mesoproterozóicas, como as do Grupo Serra do Itaberaba, durante sua ascensão para níveis crustais mais rasos.

Tabela 2. Dados analíticos de isótopos de Pb das amostras do Granito do Moinho (dados de Tassinari, 1988).

\begin{tabular}{ccccc}
\hline $\mathbf{N}^{\circ}$ campo & Material & ${ }^{206} \mathbf{P b} /{ }^{\mathbf{2 0 4}} \mathbf{P b}$ & ${ }^{{ }^{07}} \mathbf{P b} /{ }^{\mathbf{2 0 4}} \mathbf{P b}$ & ${ }^{208} \mathbf{P b} /{ }^{\mathbf{2 0 4}} \mathbf{P b}$ \\
\hline CT-13A & RT & 17,171 & 15,452 & 37,563 \\
CT-13B & RT & 17,087 & 15,450 & 37,670 \\
CT-13C & RT & 17,370 & 15,469 & 37,543 \\
CT-13D & RT & 17,372 & 15,465 & 37,700 \\
CT-13E & RT & 17,371 & 15,469 & 37,650 \\
CT-13F & RT & 17,363 & 15,472 & 38,021 \\
CT-13H & RT & 17,557 & 15,487 & 37,746 \\
CT-13I & RT & 17,361 & 15,468 & 37,752 \\
CT-13J & RT & 17,239 & 15,456 & 37,557 \\
CT-13K & RT & 17,343 & 15,469 & 37,521 \\
CT-13L & Feldspato & 16,915 & 15,486 & 37,089 \\
CT-13M & Feldspato & 17,146 & 15,521 & 37,339 \\
\hline
\end{tabular}




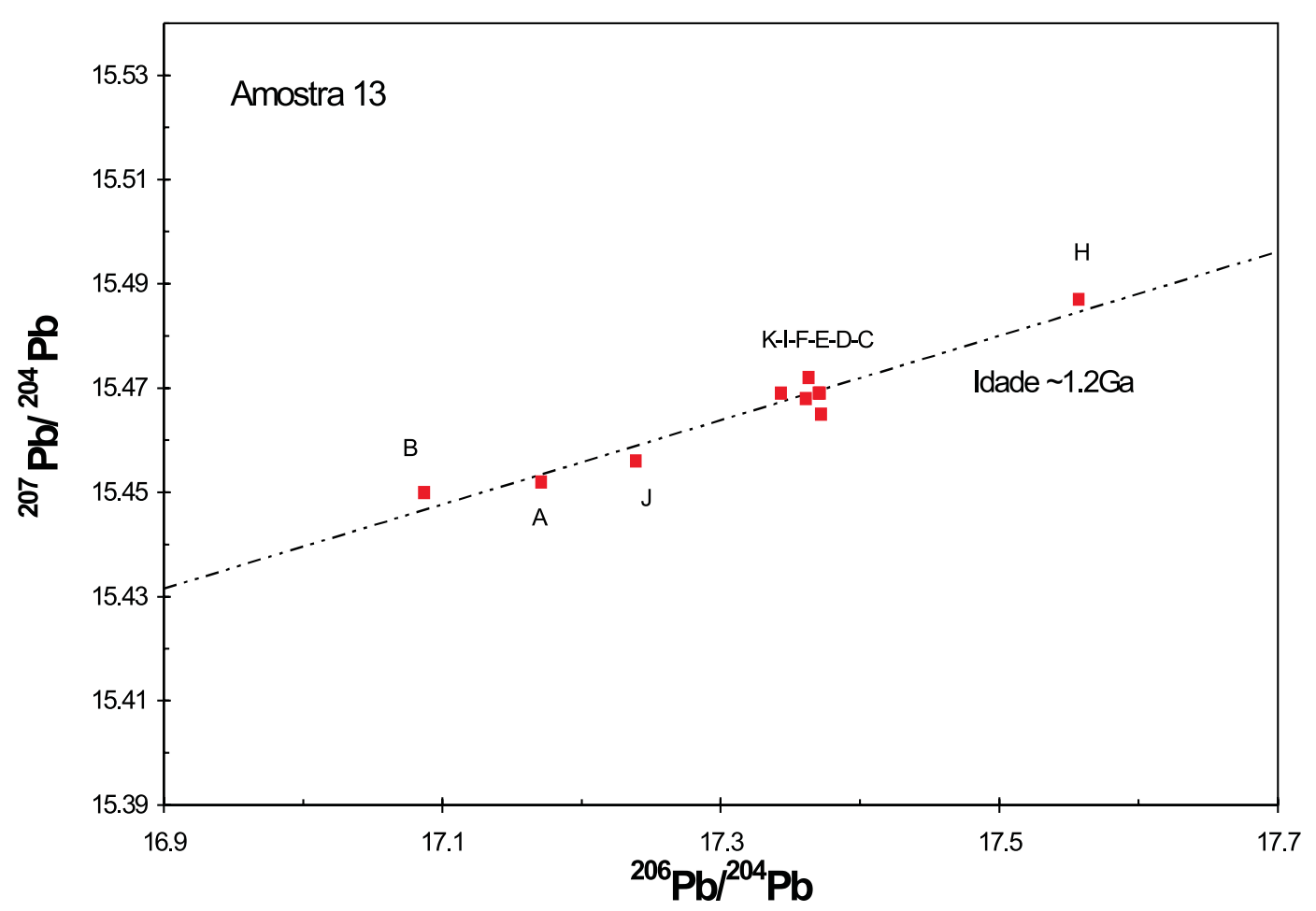

Figura 4. Diagrama $\mathrm{Pb}-\mathrm{Pb}$ em rocha total do Granito do Moinho. A inclinação da reta indica uma idade de ca. 1,2 Ga.

Tabela 3. Dados das análises Sm-Nd das amostras do Granito do Moinho.

\begin{tabular}{cccccccc}
\hline $\mathbf{N}^{\circ}$ campo & ${ }^{147} \mathbf{S m} /{ }^{144} \mathbf{N d}$ & Erro & ${ }^{143} \mathbf{N d} /{ }^{144} \mathbf{N d}$ & Erro & $\mathbf{T}_{\mathrm{DM}}(\mathbf{M a})$ & $\mathcal{E}_{(\mathbf{0})}$ & $\mathcal{E}_{(620)}$ \\
\hline SP-02 & 0,1085 & 0,0004 & 0,511602 & 0,000014 & 2,09 & $-20,21$ & $-13,23$ \\
12 & 0,1045 & 0,0006 & 0,511690 & 0,000030 & 1,89 & $-18,49$ & $-11,20$ \\
CT13J & 0,1052 & 0,0006 & 0,511523 & 0,000040 & 2,14 & $-21,75$ & $-14,51$ \\
\hline
\end{tabular}



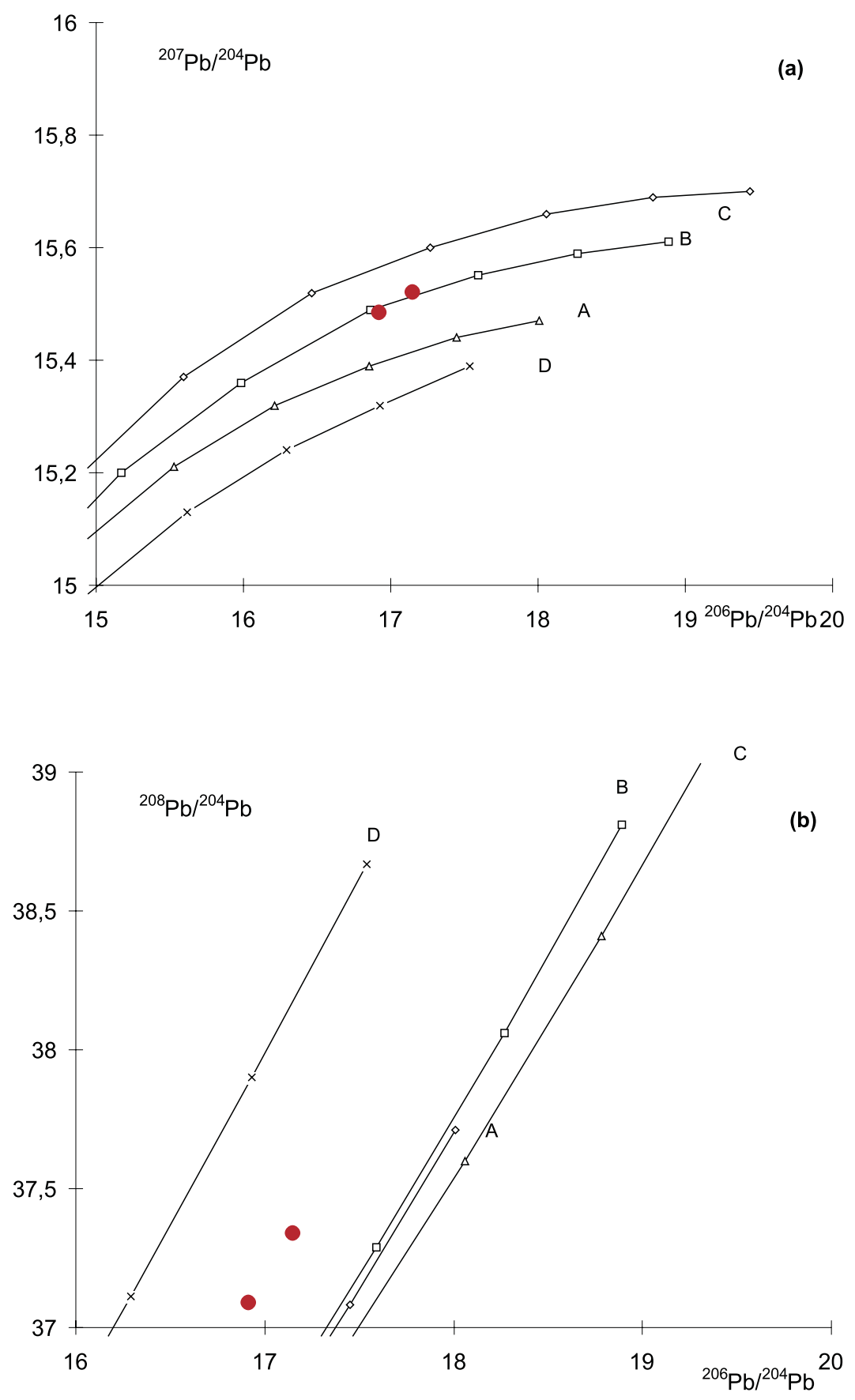

Figura 5. Diagramas ${ }^{207} \mathrm{~Pb} /{ }^{204} \mathrm{~Pb}$ versus ${ }^{206} \mathrm{~Pb} /{ }^{204} \mathrm{~Pb}$ (a) e ${ }^{208} \mathrm{~Pb} /{ }^{204} \mathrm{~Pb}$ versus ${ }^{206} \mathrm{~Pb} /{ }^{204} \mathrm{~Pb}$ (b) do Modelo da Plumbotectônica (Zartman e Doe, 1981) com as composições isotópicas determinadas nos feldspatos potássicos do $\mathrm{G}$ ranito do Moinho. $\mathbf{A}=$ Manto, $\mathbf{B}=\mathbf{O}$ rogênese, $\mathbf{C}=$ Crosta Superior, $\mathbf{D}=$ Crosta Inferior. 


\section{CONSIDERAÇÕES FINAIS}

A idade U-Pb SHRIMP de $620 \pm 11 \mathrm{Ma}$, obtida em monocristais de zircão do Granito do Moinho é pouco mais jovem do que a idade de $629 \pm 11$ Ma (Ragatki, 1997) estabelecida para o Granito do Barro Branco, de natureza sin-tectônica. Apesar destas idades serem concordantes, dentro dos erros analíticos, elas são coerentes com os estudos estruturais realizados por Campos Neto et al. (1988), que consideram a colocação do Granito do Moinho posterior à intrusão do Granito do Barro Branco. As composições isotópicas de $\mathrm{Pb}$ e $\mathrm{Nd}$ obtidas para o granitóide em estudo sugerem que a fonte do magma envolvido na formação do Granito do Moinho seria predominantemente a crosta inferior, de idade paleoproterozóica, e que, durante o processo de granitogênese, este magma teria sofrido interação com rochas da crosta superior, possivelmente de idade mesoproterozóica.

Ao analisarmos os resultados obtidos neste trabalho em conjunto com o quadro geocronológico disponível para o segmento central da Faixa de Dobramentos Ribeira, é possível constatar que o pico metamórfico na área em estudo é mais antigo do que em outras regiões localizadas mais a leste, como por exemplo, o Complexo Costeiro, na região de São Sebastião, onde o pico metamórfico ocorreu cerca de 50 Ma mais tarde (Dias Neto, 2001). Isto demonstra que a evolução termocronológica no segmento central da Faixa de Dobramento Ribeira não foi sincrônica em toda a sua extensão.

\section{AGRADECIMENTOS}

Os autores deste trabalho agradecem Pedro Refinetti Martins pela preparação das amostras e separação dos zircões e aos técnicos do Centro de Pesquisas Geocronológicas da Universidade de São Paulo pelo auxílio prestado durante os trabalhos analíticos. Os agradecimentos são também extensivos aos revisores anônimos, que com seus comentários criteriosos contribuíram para a melhoria do texto. Este trabalho foi produzido com o apoio do Projeto "Geologia Isotópica e suas Aplicações na América do Sul”, desenvolvido no âmbito do PRONEX (Programa de Núcleos de Excelência do MCT).

\section{REFERÊNCIAS BIBLIOGRÁFICAS}

ALMEIDA, F. F. M.; HASUI, Y.; BRITO NEVES, B. B. The upper Precambrian of South America. Boletim Instituto de Geociências, São Paulo, n. 7, p. 45-80, 1976.

BABINSKI, M.; TASSINARI, C. C. G., NUTMAN, A. P.; SATO, K.; MARTINS, P. R.; IYER, S. S. U/Pb SHRIMP zircon ages of migmatites from the basement of the Embu
Complex, Ribeira fold belt, Brazil: Indications for $~ 1.4-$ 1.3Ga Pb-Pb and $\mathrm{Rb}-\mathrm{Sr}$ "isochron" ages of no geological meaning. In: SOUTH AMERICAN SYMPOSIUM ON ISOTOPE GEOLOGY, 2., 2001. Pucón. Extended Abstracts. Pucón: Sociedad Geologica de Chile, 2001. p. 91-93.

CAMPOS NETO, M. C.; BASEI, M. A. S.; ARTUR, A.C.; MACHADO, R.; DIAS NETO, C. M.; FRAGOSOCÉSAR, R.; SOUZA, A. P. Geologia das Folhas Piracaia e Igaratá. In: JORNADA SOBREACARTA GEOLÓGICADO ESTADO DE SÃO PAULO em 1: 50 000, 1., 1983.Atas. São Paulo: SICT, Pró-Minério - IPT, 1983. p. 61 - 78.

CAMPOS NETO, M. C.; FIGUEIREDO, M. C.H. The Rio Doce Orogeny, Southeastern Brazil. Journal of South American Earth Sciences, v. 8, n. 2 p. 143-162, 1995.

COMPSTON, W.; WILLIAMS, I. S.; MEYER, C. U-Pb Geochronology of zircons from lunar breccia 73217 using a sensitive high mass-resolution ion microprobe. Journal of Geophysical Research B, v. 89, Suppl., p. 525-534, 1984.

CUMMING, G. L.; RICHARDS, J. R. Ore Lead ratios in a continuously changing Earth. Planetary Science Letters, v. 28, p. 155-171, 1975.

DANTAS, E. L.; HACKSPACHER, P. C.; FETTER, A. H.; SATO, K.; PIMENTEL, M.; GODOY, A. M. Nd isotope systematics related to Proterozoic evolution of the central Ribeira Belt in the State of São Paulo, SE Brazil. Revista Brasileira de Geociências, v. 30, n. 1, p. 40-43, 2000.

DePAOLO, D. J. A neodymium and strontium isotopic study of the Mesozoic calc-alkaline granitic batholiths of the Sierra Nevada and Peninsular Ranges, California. Journal of Geophysical Research, v. 86, p. 10470-10488, 1981.

DIAS NETO, C. M. Evolução tectono-termal do Complexo Costeiro (Faixa de Dobramentos Ribeira), em São Paulo. 2001. $160 \mathrm{f}$. Tese (Doutorado) - Instituto de Geociências, Universidade de São Paulo, São Paulo.

FIGUEIREDO, M. C. H.; BERGMAN, M.; PENALVA, F.; TASSINARI, C. C. G. Ocorrência de "pillow lavas" no Grupo São Roque, Estado de São Paulo. Ciências da Terra, v. 2, p. 6-8, 1982.

HACKSPACHER, P.; DANTAS, E. L.; SPOLADORE, A.; FETTER, A. H.; OLIVEIRA, M. A. F. Evidence of Neoproterozoic backarc basin development in the Central Ribeira Belt, Southeastern Brazil: New geochronological and Geochemical constrains from the São Roque - Açungui Groups. Revista Brasileira de Geociências, v. 30, n. 1, p. 110-114, 2000.

HOUSH, T.; BOWRING, S. A. Lead isotopic heterogeneities within alkali feldspars: implications for the determination of initial lead isotopic compositions. Geochimica et Cosmochimica Acta, v. 55, p. 2309-2316, 1991.

JANASI, V.; ULBRICH, H. H. G. J. Avaliação para as informa- 
ções disponíveis para os granitóides do Estado de São Paulo. In: SIMPÓSIO REGIONAL DE GEOLOGIA, 5., 1992. São Paulo. Anais. São Paulo: SBG, 1992. v. 1, p. 133-146.

JULIANI, C. Geologia, petrogênese e aspectos metalogenéticos dos Grupos Serra do Itaberaba e São Roque na região das Serras do Itaberaba e Pedra Branca, NE da cidade de São Paulo, SP. 1993. 2v. Tese (Doutorado) - Instituto de Geociências, Universidade de São Paulo. São Paulo.

JULIANI, C.; HACKSPACHER, P. C.; DANTAS, E. L.; FETTER, A. H. The Mesoproterozoic volcano-sedimentary Serra do Itaberaba Group of the Central Ribeira Belt, São Paulo State, Brazil: Implications for the age of the overlying São Roque Group. Revista Brasileira de Geociências, v. 30, n. 1, p. 82-86, 2000.

INSTITUTO DE PESQUISAS TECNOLÓGICAS. Projeto Ouro Tapera Grande, Pesquisa de Detalhe, São Paulo: IPT, 1984.3v. (Relatório Interno n. 20715)

LUDWIG, K. R. Isoplot/Ex. Berkeley: Geochronological Center, 1998. (Special Publication n. 1).

PACES, J. B.; MILLER Jr., J. D. Precise U-Pb ages of Duluth Complex and related mafic intrusions, northeastern Minnesota: Geochronological insights to physical petrogenetic, paleomagnetic and tectonomagmatic processes associated with the $1.1 \mathrm{Ga}$ midcontinent rift system. Journal Geophysical Research, v. 98, p. 13997-14013, 1993.

RAGATKY, D. Contribuição à Geoquímica e Geocronologia do Domínio São Roque e da Nappe de Empurrão Socorro - Guaxupé, na Região de Igaratá e Piracaia, SP. 1997. 130 f. Tese (Doutorado) - Instituto de Geociências,.Universidade de São Paulo, São Paulo.

SATO, K.; TASSINARI, C. C. G.; KAWASHITA, K.; PETRONILHO, L. O método geocronológico Sm-Nd no IGc - USP e suas aplicações. Anais da Academia Brasileira de Ciências, v. 3, n. 67, p. 313-336, 1995.

STEIGER, R. H.; JÄGER, E. Subcomission on geochronology: convention on the use of decay constants in geochronology and cosmochronology. Earth Planetary Science Letters, v. 36, p. 359-362, 1977.

STERN, R. A. High-resolution SIMS determination of radiogenic trace-isotope ratios in minerals. In: CABRI, L. J.; VAUGHAN, D. J. (Eds.) Modern approaches to ore and environmental mineralogy. Mineralogical Association of Canada, Short course, Série, 27, p. 241-268, 1998.

STRECKEISEN, A. To each plutonic rock its proper name. Earth Sciences Review, v. 12, n. 1, p. 1-33, 1976.

TASSINARI, C. C. G. As idades das rochas e dos eventos metamórficos da porção Sudeste do Estado de São Paulo e sua evolução crustal. 1988. 236 f. Tese (Doutorado) - Instituto de Geociências, Universidade de São Paulo. São Paulo.
TASSINARI, C.C.G.; CAMPOS NETO, M. (1988) Precambrian continental crust evolution of Southeastern São Paulo State, Brazil: Based on isotopic evidences. Geochimica Brasiliensis, v. 2, n. 2, p. 175-183, 1988.

TASSINARI, C. C. G.; SATO, K. Idades de formação de crosta continental na parte sudeste do Estado de São Paulo, com base em dados Sm-Nd. In: CONGRESSO BRASILEIRODE GEOLOGIA, 39., 1996. Salvador.Anais. Salvador: SBG, 1996. v. 6, p. 489 - 491.

TASSINARI, C. C. G., MUNHÁ, J. M. U.; RIBEIRO, A. A.; CORREIA, C. T. Neoproterozoic oceans in the Ribeira Belt (southeastern Brazil): The Pirapora do Bom Jesus Ophiolitic Complex. Episodes, v. 24, n. 4, p. 245-251, 2001.

VAVRA, G. On the kinematics of zircons growth and its petrogenetic significance: a cathodoluminescence study. Contributions to Mineralogy and Petrology, v. 106, p. 90-99, 1990.

WILLIAMS, I. S. U-Th-Pb geocronology by ion microprobe. In applications of microanalytical techniques to understanding minerlizing processes. Society Economic Geologists, Short Course 7, p. 1-35., 1998.

ZARTMAN, R. E.; DOE, B. R. Plumbotectonics: the Model. Tectonophysics, v. 75, p. 135-162, 1981. 